\title{
Effect of thermal conversion of pig manure and poultry litter on the content and mobility of Mn and Fe in biochars and in soil after their application
}

Krzysztof Gondek $^{1}$, and Monika Mierzwa-Hersztek ${ }^{1 *}$

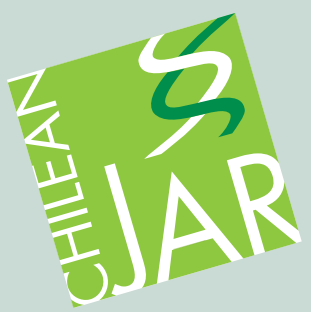

\section{ABSTRACT}

By-products of animal breeding and raising can contain considerable amounts of trace elements, including $\mathrm{Mn}$ and $\mathrm{Fe}$, due to the fact that their amounts in fodders are purposefully being increased. Thermal conversion of pig manure and poultry litter may have a significant effect on changes in the content and mobility of $\mathrm{Mn}$ and $\mathrm{Fe}$ in these materials. The aim of the research was to evaluate the effect of thermal conversion of pig manure and poultry litter on the content and mobility of $\mathrm{Mn}$ and $\mathrm{Fe}$ in biochars and in soil after their application $(0.5 \%, 1 \%$, and $2 \%$ amendments to the soil). As a result of thermal conversion of pig manure and poultry litter, an increase in the content of total forms and a reduction of $\mathrm{Mn}$ and $\mathrm{Fe}$ forms extracted with water were recorded. The $2 \%$ amendment of pig manure biochar to soil caused an increase in the content of mobile forms of $\mathrm{Fe}$, whereas poultry litter biochar decreased mobility of this element. Introduction of pig manure biochar and poultry litter biochar to the soil caused a similar immobilization of mobile forms of $\mathrm{Mn}$ as in the case of application of thermally unprocessed manure and litter. It has been shown that the content of $\mathrm{Fe}$ and $\mathrm{Mn}$ extracted with $0.025 \mathrm{M}$ $\mathrm{C}_{10} \mathrm{H}_{22} \mathrm{~N}_{4} \mathrm{O}_{8}$ was higher than the content of these elements extracted with $1 \mathrm{M} \mathrm{NH}_{4} \mathrm{NO}_{3}$.

Key words: Biochar, iron, manganese, pig manure, poultry litter, soil.

${ }^{1}$ University of Agriculture in Krakow, Department of Agricultural and Environmental Chemistry, Al. Mickiewicza 21, 31-120 Krakow, Poland. *Corresponding author (monika6_mierzwa@wp.pl).

Received: 23 December 2015

Accepted: 25 April 2016.

doi:10.4067/S0718-58392016000300013

\section{INTRODUCTION}

Chemical composition of biochars is significantly varied and depends on the chemical composition of biomass used for their production and on conditions of the thermal conversion process (Enders et al., 2012). In terms of chemical composition, biochars differ not only among themselves, but from other types of organic matter (OM). The difference is that they contain much higher amounts of aromatic $\mathrm{C}$ compounds. Biochar also contains a mineral fraction composed of macroelements and trace elements which are important for using these materials for fertilizing purposes (Lehmann et al., 2011). Due to technological parameters of the thermal conversion process, especially temperature, one can obtain products that differ not only in physical properties, but also in the content of substances which are easily decomposed in soil conditions (Jindo et al., 2014). By-products of animal breeding and raising can contain considerable amounts of trace elements, including $\mathrm{Mn}$ and $\mathrm{Fe}$, due to the fact that their amounts in fodders are purposefully being increased (Commission Regulation, 2003). Under conditions of thermal conversion of manure and poultry litter, it is possible to increase the content and mobility of $\mathrm{Mn}$ and $\mathrm{Fe}$. On one hand, it results from loss of OM (compaction effect). On the other hand, it is caused by degradation of various compounds and formation of new or activation of initially unavailable chemically bound substances or elements (Al-Wabel et al., 2013).

Total content of $\mathrm{Mn}$ and $\mathrm{Fe}$ in soils is high and may reach several percent in the case of $\mathrm{Fe}$. These elements are used by plants in small amounts (Walna et al., 2010). In the soil environment, $\mathrm{Mn}$ and $\mathrm{Fe}$ form numerous compounds and their bioavailability is conditioned by soil properties, mainly by the redox potential and $\mathrm{pH}$ (Xue et al., 2006). According to Livens (1991), Mn and Fe, which can be found in topsoils, can form complex bonds with $\mathrm{OM}$ and remain available for plants in this form. This theory is confirmed by results of research conducted by Kobierski (2004), where the highest amounts of $\mathrm{Mn}$ and Fe forms extracted with DTPA were determined in topsoils. Xue et al. (2006) point to the existence of a relationship between $\mathrm{Fe}$ and the OM content, while at the same time stressing the possibility that this phenomenon may be intensified as a result of OM accumulation in soil. The cited authors do not, however, point to a connection between $\mathrm{OM}$ and $\mathrm{Mn}$ ions.

Taking into account a multitude of trace elements occurring in soil, more and more attention is being focused on the ones with the highest impact on the environment, in other words: $\mathrm{Cd}, \mathrm{Pb}$, $\mathrm{Cu}$, and $\mathrm{Zn}$. Manganese and $\mathrm{Fe}$ have a slightly weaker negative effect on the environment. That is why there are few papers 
concerning the content and bioavailability of these elements. However, determination of the content and mobility of $\mathrm{Mn}$ and $\mathrm{Fe}$ in soil may provide information on the effect of some anthropogenic elements on the natural environment. It should also be remembered that both of these elements are extremely important in terms of influencing the bioavailability of other trace metals (Samsuri et al., 2013).

Considering the physical properties of biochar as well as considerable OM content, this material more and more often is used as a sorbent and reservoir of mineral substances (Ahmad et al., 2014a; 2014b). Thermal conversion of pig manure and poultry litter may have a significant effect on changes in the content and mobility of $\mathrm{Mn}$ and Fe in these materials. However, functional groups which are present on the surface of biochar can "control" the content of mobile forms of trace elements in these materials and in soil by forming specific complexes (Han et al., 2013). One can therefore expect a beneficial effect of biochar on the process of stabilization of mobile forms of $\mathrm{Mn}$ and $\mathrm{Fe}$ in soil. Therefore the aim of this research was to evaluate the effect of thermal conversion of pig manure and poultry litter on the content and mobility of $\mathrm{Mn}$ and $\mathrm{Fe}$ in biochars and in soil after their application.

\section{MATERIAL AND METHODS}

\section{Soil and amendments collection}

The research was conducted on soil which had a natural content of $\mathrm{Mn}$ and $\mathrm{Fe}$ collected from a 0-20 cm layer from an area of southern Poland. Properties of the soil used in the research are presented in Table 1.

Thermal conversion of pig manure (PM) and poultry litter (PL) was conducted in laboratory conditions, at a station designed for thermal conversion of biomass at reduced air access (1\%-2\%) (IBI, 2012). Temperature inside the combustion chamber was $300 \pm 10^{\circ} \mathrm{C}$. The exposure time was $15 \mathrm{~min}$. The speed of heating of the combustion chamber was $10^{\circ} \mathrm{C} \mathrm{min}-1$. Selection of time and temperature of pyrolysis was done according to our preliminary research and results of other authors' research (Al-Wabel et al., 2013; Gondek et al., 2014).

\section{Chemical analysis of soil}

Mobile forms of $\mathrm{Mn}$ and $\mathrm{Fe}$ were extracted from the soil with $1 \mathrm{M} \mathrm{NH} \mathrm{NHO}_{3}$ solution (soil:solution = 1:2.5) for

Table1. Selected chemical and physical properties of soil.

\begin{tabular}{|c|c|}
\hline $\mathrm{pH} \mathrm{H} \mathrm{H}_{2} \mathrm{O}$ & $5.79 \pm 0.07$ \\
\hline $\mathrm{pH} \mathrm{KCl}$ & $4.60 \pm 0.01$ \\
\hline Electrical conductivity, $\mu \mathrm{S} \mathrm{cm}-1$ & $21.0 \pm 9.0$ \\
\hline Total C, $\%$ & $0.42 \pm 0.01$ \\
\hline Total N, \% & $0.087 \pm 0.004$ \\
\hline Total Mn, $\mathrm{mg} \mathrm{kg}^{-1}$ & $198 \pm 10$ \\
\hline Total Fe, $\mathrm{mg} \mathrm{kg}^{-1}$ & $2515 \pm 6$ \\
\hline Sand, $\mathrm{g} \mathrm{kg-1}$ & $870 \pm 56$ \\
\hline Silt, $\mathrm{g} \mathrm{kg}^{-1}$ & $80 \pm 6$ \\
\hline Clay, $\mathrm{g} \mathrm{kg}^{-1}$ & $50 \pm 4$ \\
\hline
\end{tabular}

Each value represents the mean of three replicates \pm standard deviation.
$2 \mathrm{~h}$ (Park et al., 2011). Content of the studied metals in bonds with OM was determined using sequential chemical extraction developed by Zeien and Brümmer (1989) in which forms joined in bonds with $\mathrm{OM}$ were extracted with $0.025 \mathrm{M} \mathrm{C}_{10} \mathrm{H}_{22} \mathrm{~N}_{4} \mathrm{O}_{8}$ solution, $\mathrm{pH}=4.6$ (soil:solution = 1:25) for $90 \mathrm{~min}$.

The extraction force of $\mathrm{NH}_{4} \mathrm{NO}_{3}$ is comparable to the ability of plants to take up trace elements from the soil solution. The use of $\mathrm{C}_{10} \mathrm{H}_{22} \mathrm{~N}_{4} \mathrm{O}_{8}$ (as the next extractant in the chemical extraction sequence) makes it possible to determine the content of organic matter-bound forms of trace elements. Since the complex organic component is likely to be degraded (as a result of mineralization), determination of this fraction of trace elements may increase the pool of heavy metals available for plants in soil. As stated by AlWabel et al. (2015), the analysis made with the use of such extractants is a reliable test for examining the actual and potential bioavailability of heavy metals for plants.

\section{Chemical analysis of amendments}

In order to characterize the properties of PM, biochar produced from pig manure (PMB), PL as well as of biochar produced from poultry litter (PLB), all of which were used in the research, the materials were ground in a laboratory mill (with a $1 \mathrm{~mm}$ screen), and then dried at $105^{\circ} \mathrm{C}$ for $12 \mathrm{~h}$ (Jindo et al., 2012) and subjected to analyses. The $\mathrm{pH}$ of the materials (material:water $=1: 5$ ) was determined electrochemically using a pH meter (pH-Meter $\mathrm{CP}-505$, Elmetron Sp.jul., Zabrze), electrical conductivity (EC; material: water $=1: 5$ ) was determined using a conductivity meter (CCO-501 Conductivity/Oxygen meter, Hotek Technologies, Tacoma, Washington, USA) (Meier et al., 2015), and content of total forms of $\mathrm{N}, \mathrm{C}$, and $\mathrm{S}$ was determined on analyzer (vario MAX cube CNS, Elementar Analysensysteme $\mathrm{GmbH}$, Hanau, Germany). The total contents of $\mathrm{Mn}$ and Fe were determined after incinerating the sample in a chamber furnace at $450{ }^{\circ} \mathrm{C}$ for $12 \mathrm{~h}$ and mineralization of the residue in a mixture of concentrated nitric and perchloric acid (3:2) $(\mathrm{v} / \mathrm{v})$. The content of bioavailable forms in organic materials was determined after a 24-h extraction (at room temperature) of the sample with redistilled water (material: water $=1: 5$ ) (Gondek et al., 2014). Concentration of the studied elements in the obtained solutions was determined by inductively coupled plasma optical emission spectrometry (Optima 7300 DV, ICP-OES spectrometers, Perkin Elmer, Waltham, Massachusetts, USA) (Oleszczuk et al., 2007). Specific surface area of organic materials as well as size and volume of pores were determined using an Accelerated Surface Area and Porosimetry Analyzer (ASAP 2010, Micromeritics Instrument Corporation, Norcross, Georgia, USA). Specific surface area was determined using physical adsorption of $\mathrm{N}$ at liquid nitrogen temperature $\left(77^{\circ} \mathrm{K}\right)$ from the BrunauerEmmet-Teller $\left(\mathrm{S}_{\mathrm{BET}}\right)$ equation. Prior to measurement $\left(\mathrm{S}_{\mathrm{BET}}\right)$, studied samples were subjected to desorption at $105{ }^{\circ} \mathrm{C}$ in vacuum and rinsed with pure He. Sample degassing time was $16 \mathrm{~h}$. The surface degassing state was controlled in automatic mode (Barrett et al., 1951). 


\section{Incubation study of soil, experimental design and analysis}

Incubation tests were carried out in $100 \mathrm{~g}$ analytical samples of soil amended with $0.5 \%, 1 \%$, and $2 \%$ of the abovementioned organic materials: PM, PMB, PL, PLB. Moisture of a sample was maintained at $60 \%$ of soil water capacity. The control sample was kept without amendment of organic materials. The soil samples were incubated for $150 \mathrm{~d}$ at 25 $\pm 0.10{ }^{\circ} \mathrm{C}$. The following were determined in the samples after incubation: soil $\mathrm{pH}$ - potentiometrically in a soil and water suspension and in a suspension of the soil and $1 \mathrm{M}$ $\mathrm{KCl}$ solution (soil:solution = 1:2.5); $\mathrm{EC}$ - by conductometer; and cation exchange capacity (CEC) by Kappen method (Jaremko and Kalembasa, 2014).

\section{Statistical analysis}

The experiment was done in triplicate. The obtained data were elaborated by means of STATISTICA 12 software (StatSoft, Tulsa, Oklahoma, USA). Mean values of the analyzed properties were compared using a multiple Duncan test at the significance level of $p \leq 0.05$. Variation within treatments was determined by calculating the values of standard deviation $( \pm \mathrm{SD})$.

\section{RESULTS AND DISCUSSION}

\section{Incubation study}

Sandy acid soil containing $198 \mathrm{mg} \mathrm{Mn} \mathrm{kg}^{-1} \mathrm{DM}$ and $2515 \mathrm{mg}$ $\mathrm{Fe} \mathrm{kg}{ }^{-1} \mathrm{DM}$ was used for the research. The total $\mathrm{C}$ content and total $\mathrm{N}$ content amounted to $0.42 \%$ and $0.087 \%$, respectively (Table 1). The application of organic materials caused an increase in the contents of total $\mathrm{C}$ and $\mathrm{N}$ compared to the control soil (Table 2). The contents of both studied elements increased in line with the amendment of organic material to the soil. The value of $\mathrm{C}: \mathrm{N}$ ratio for non-converted organic materials PM and PL applied into the soil was reduced with an increase in the amendment. An inverse relationship was observed for biochars BPM and BPL.

\section{Chemical characterization}

Pig manure (PM) and PL had lower $\mathrm{pH}$ values and lower values of electrical conductivity (EC) in comparison to biochars obtained from these materials PMB and PLB
Table 2. Content of total $\mathrm{C}$, total $\mathrm{N}$, and ratio $\mathrm{C}: \mathrm{N}$ in soil after incubation.

\begin{tabular}{llll}
\hline Treatment & \multicolumn{1}{c}{$\mathrm{C}_{\text {Tот }}$} & \multicolumn{1}{c}{$\mathrm{N}_{\text {TOт }}$} & \multicolumn{1}{c}{$\mathrm{C}: \mathrm{N}$} \\
\cline { 2 - 3 } & \multicolumn{2}{c}{$\%$} & \\
Soil & $0.43 \pm 0.05 \mathrm{a}$ & $0.054 \pm 0.002 \mathrm{a}$ & $7.90 \pm 0.90 \mathrm{abcd}$ \\
Soil + PM 0.5\% & $0.56 \pm 0.01 \mathrm{~cd}$ & $0.065 \pm 0.003 \mathrm{~b}$ & $8.70 \pm 0.39 \mathrm{de}$ \\
Soil + PM 1\% & $0.61 \pm 0.02 \mathrm{de}$ & $0.075 \pm 0.001 \mathrm{de}$ & $8.16 \pm 0.17 \mathrm{~cd}$ \\
Soil + PM 2\% & $0.86 \pm 0.07 \mathrm{~g}$ & $0.103 \pm 0.006 \mathrm{~g}$ & $8.36 \pm 0.24 \mathrm{de}$ \\
Soil + BPM 0.5\% & $0.58 \pm 0.03 \mathrm{cde}$ & $0.073 \pm 0.011 \mathrm{cde}$ & $8.01 \pm 0.78 \mathrm{bcd}$ \\
Soil + BPM 1\% & $0.76 \pm 0.01 \mathrm{f}$ & $0.090 \pm 0.001 \mathrm{f}$ & $8.49 \pm 0.09 \mathrm{de}$ \\
Soil + BPM 2\% & $1.04 \pm 0.03 \mathrm{~h}$ & $0.115 \pm 0.002 \mathrm{~h}$ & $9.10 \pm 0.26 \mathrm{e}$ \\
Soil + PL 0.5\% & $0.48 \pm 0.01 \mathrm{ab}$ & $0.066 \pm 0.003 \mathrm{bc}$ & $7.29 \pm 0.33 \mathrm{ab}$ \\
Soil + PL 1\% & $0.54 \pm 0.03 \mathrm{bc}$ & $0.072 \pm 0.006 \mathrm{bcde}$ & $7.48 \pm 0.27 \mathrm{abc}$ \\
Soil + PL 2\% & $0.71 \pm 0.04 \mathrm{f}$ & $0.099 \pm 0.004 \mathrm{~g}$ & $7.14 \pm 0.35 \mathrm{a}$ \\
Soil + BPL 0.5\% & $0.57 \pm 0.02 \mathrm{~cd}$ & $0.069 \pm 0.004 \mathrm{bcd}$ & $8.24 \pm 0.25 \mathrm{~cd}$ \\
Soil + BPL 1\% & $0.64 \pm 0.03 \mathrm{e}$ & $0.079 \pm 0.003 \mathrm{e}$ & $8.15 \pm 0.32 \mathrm{~cd}$ \\
Soil + BPL 2\% & $0.85 \pm 0.04 \mathrm{~g}$ & $0.099 \pm 0.003 \mathrm{~g}$ & $8.64 \pm 0.63 \mathrm{de}$ \\
\hline Ea
\end{tabular}

Each value represents the mean of three replicates \pm standard deviation. The different letters within a column indicate a significant difference at $p \leq 0.05$ according to Duncan's multiple range tests.

PM: Pig manure, PL: poultry litter, PMB: pig manure biochar, PLB: poultry litter biochar.

(Table 3). The pig manure biochar (PMB) and PLB were found to have higher total N, C, and S contents as well as higher specific surface area $\left(\mathrm{S}_{\mathrm{BET}}\right)$ as compared to materials not subjected to pyrolysis. Similar $\mathrm{S}_{\mathrm{BET}}$ for PL produced at $350{ }^{\circ} \mathrm{C}$ was obtained by Novak et al. (2009). Thermal conversion of PL and PM also led to an increase in pore diameter. Compared to PMB, pore volume of PLB was higher by $38 \%$, while pore diameter, lower by $14 \%$.

\section{Manganese and iron content in pig manure and in biochar}

Manganese content in the PM was lower than in PL (Table 4). The determined content of total forms of $\mathrm{Mn}$ in biochars was significantly higher. The increase in Mn content in relation to $\mathrm{PM}$ was more than $50 \%$ in the case of PMB, and more than $37 \%$ in the case of PL and PLB. As a result of thermal conversion of PM and PL, a reduction in the content of Mn forms extracted with water was observed. The content of total forms of $\mathrm{Fe}$ in the studied materials was higher than the determined Mn content (Table 4). Relatively greater amounts of available forms of this element were extracted from organic materials. A similar tendency as in the case of Mn was observed, namely a tendency of increasing content of total forms of $\mathrm{Fe}$ as a result of thermal conversion of PM and PL, and of reducing Fe forms extracted with water in

Table 3. Selected properties of organic materials.

\begin{tabular}{|c|c|c|c|c|}
\hline Properties & Pig manure & $\begin{array}{c}\text { Pig manure } \\
\text { derived biochar }\end{array}$ & Poultry litter & $\begin{array}{c}\text { Poultry litter } \\
\text { derived biochar }\end{array}$ \\
\hline Dry matter, $\%$ & $17.8 \pm 0.1$ & $97.9 \pm 0.2$ & $32.3 \pm 1.7$ & $98.6 \pm 0.2$ \\
\hline $\mathrm{pH}\left(\mathrm{H}_{2} \mathrm{O}\right)$ & $7.56 \pm 0.01$ & $8.32 \pm 0.00$ & $7.53 \pm 0.02$ & $8.41 \pm 0.02$ \\
\hline Electric conductivity, $\mu \mathrm{S} \cdot \mathrm{cm}^{-1}$ & $20.3 \pm 3.6$ & $77.7 \pm 17.8$ & $49.1 \pm 12.4$ & $91.5 \pm 2.6$ \\
\hline Total N, \% & $3.14 \pm 0.04$ & $3.49 \pm 0.05$ & $2.51 \pm 0.17$ & $3.27 \pm 0.07$ \\
\hline Total C, \% & $37.0 \pm 0.3$ & $39.8 \pm 0.6$ & $32.3 \pm 0.3$ & $37.7 \pm 0.3$ \\
\hline Total S, \% & $0.47 \pm 0.02$ & $0.36 \pm 0.05$ & $0.16 \pm 0.02$ & $0.18 \pm 0.02$ \\
\hline Specific surface area $\left(\mathrm{S}_{\mathrm{BET}}\right), \mathrm{m}^{2} \mathrm{~g}^{-1}$ & $1.62 \pm 0.10$ & $2.05 \pm 0.19$ & $1.83 \pm 0.22$ & $2.76 \pm 0.29$ \\
\hline Pore volume, $\mathrm{cm}^{3} \mathrm{~g}^{-1}$ & $0.007 \pm 0.000$ & $0.008 \pm 0.001$ & $0.006 \pm 0.000$ & $0.011 \pm 0.002$ \\
\hline Pore diameter, nm & $15 \pm 1$ & $21 \pm 3$ & $14 \pm 2$ & $18 \pm 3$ \\
\hline
\end{tabular}

Each value represents the mean of three replicates \pm standard deviation.

$\mathrm{S}_{\mathrm{BET}}$ : Specific surface area determined by Brunauer-Emmet-Teller equation. 
Table 4. Manganese and Fe content in pig manure, poultry litter, and biochars.

\begin{tabular}{|c|c|c|c|c|}
\hline Content & Pig manure & $\begin{array}{c}\text { Pig manure } \\
\text { derived biochar }\end{array}$ & Poultry litter & $\begin{array}{c}\text { Poultry litter } \\
\text { derived biochar }\end{array}$ \\
\hline Total Mn, $\mathrm{mg} \mathrm{kg}^{-1}$ & $214 \pm 17$ & $321 \pm 15$ & $351 \pm 33$ & $482 \pm 79$ \\
\hline $\mathrm{Mn}-\mathrm{H}_{2} \mathrm{O}, \mathrm{mg} \mathrm{kg}^{-1}$ & $6.19 \pm 0.58$ & $2.69 \pm 0.27$ & $5.28 \pm 0.30$ & $1.16 \pm 0.00$ \\
\hline $\mathrm{Mn}-\mathrm{H}_{2} \mathrm{O}$ in total $\mathrm{Mn}, \%$ & 2.83 & 0.83 & 1.50 & 0.24 \\
\hline Total Fe, $\mathrm{mg} \mathrm{kg}^{-1}$ & $2754 \pm 272$ & $7412 \pm 656$ & $1052 \pm 60$ & $1611 \pm 214$ \\
\hline $\mathrm{Fe}-\mathrm{H}_{2} \mathrm{O}, \mathrm{mg} \mathrm{kg}^{-1}$ & $142 \pm 7$ & $11.0 \pm 0.7$ & $74.8 \pm 11$ & $6.6 \pm 0.6$ \\
\hline $\mathrm{Fe}-\mathrm{H}_{2} \mathrm{O}$ in total $\mathrm{Fe}, \%$ & 5.15 & 0.14 & 7.11 & 0.40 \\
\hline
\end{tabular}

Each value represents the mean of three replicates \pm standard deviation.

PMB and PLB. Results obtained by Hossain et al. (2011) indicate that the content of trace elements increases during pyrolysis, depending on the used temperature, which corresponds with mass loss. In the conducted research, the temperature used $\left(300{ }^{\circ} \mathrm{C}\right)$ also caused an increase in the content of total forms of $\mathrm{Mn}$ and $\mathrm{Fe}$ and a reduction in the content of $\mathrm{Mn}$ and $\mathrm{Fe}$ forms extracted with water. According to He et al. (2010), pyrolysis temperature above $350{ }^{\circ} \mathrm{C}$ leads to higher stability of trace element forms. On the other hand, according to Song and Guo (2012), suggested temperature, for agricultural purposes, of pyrolysis of materials should be approximately $300^{\circ} \mathrm{C}$.

\section{Soil pH, EC, and cation exchange capacity (CEC)}

The $\mathrm{pH}$ values determined in the soil and water suspension and in the suspension of the soil and $\mathrm{KCl}$ solution depended on the type and quantity of the applied material (Table 5). Application of organic materials caused considerable reduction of soil acidification. Increasing the addition of organic material to the soil brought about greater and greater increases in $\mathrm{pH}$, determined both in the soil and water suspension and in the suspension of the soil and $\mathrm{KCl}$ solution. When comparing the effect of PM and PL with biochars (PMB, PLB) produced from these materials, a significantly

Table 5. Soil pH, electrical conductivity (EC), and cation exchange capacity (CEC).

\begin{tabular}{llllr}
\hline Treatment & $\mathrm{pH}\left(\mathrm{H}_{2} \mathrm{O}\right)$ & $\mathrm{pH}(\mathrm{KCl})$ & $\mathrm{EC}$ & $\mathrm{CEC}$ \\
\hline & & & $\mu \mathrm{S} \mathrm{cm} \mathrm{c}^{-1}$ & $\mathrm{mmol} \mathrm{kg}^{-1}$ \\
Soil & $5.04 \pm 0.03 \mathrm{a}$ & $4.46 \pm 0.01 \mathrm{a}$ & $146 \pm 34 \mathrm{a}$ & $89 \pm 3 \mathrm{a}$ \\
Soil + PM 0.5\% & $5.60 \pm 0.04 \mathrm{~b}$ & $4.87 \pm 0.02 \mathrm{~b}$ & $389 \pm 14 \mathrm{abc}$ & $93 \pm 3 \mathrm{ab}$ \\
Soil + PM 1\% & $5.88 \pm 0.04 \mathrm{c}$ & $5.27 \pm 0.06 \mathrm{c}$ & $649 \pm 22 \mathrm{cde}$ & $101 \pm 3 \mathrm{ab}$ \\
Soil + PM 2\% & $6.41 \pm 0.05 \mathrm{e}$ & $6.07 \pm 0.11 \mathrm{e}$ & $992 \pm 17 \mathrm{~g}$ & $108 \pm 4 \mathrm{bc}$ \\
Soil + BPM 0.5\% & $6.07 \pm 0.05 \mathrm{~d}$ & $5.45 \pm 0.03 \mathrm{~d}$ & $369 \pm 84 \mathrm{ab}$ & $93 \pm 5 \mathrm{ab}$ \\
Soil + BPM 1\% & $6.47 \pm 0.03 \mathrm{f}$ & $6.08 \pm 0.05 \mathrm{e}$ & $574 \pm 58 \mathrm{bcde}$ & $103 \pm 8 \mathrm{ab}$ \\
Soil + BPM 2\% & $7.09 \pm 0.02 \mathrm{~h}$ & $6.79 \pm 0.02 \mathrm{~g}$ & $799 \pm 158 \mathrm{efg}$ & $120 \pm 1 \mathrm{c}$ \\
Soil + PL 0.5\% & $5.94 \pm 0.05 \mathrm{c}$ & $5.36 \pm 0.03 \mathrm{~cd}$ & $505 \pm 11 \mathrm{~cd}$ & $100 \pm 7 \mathrm{ab}$ \\
Soil + PL 1\% & $6.37 \pm 0.00 \mathrm{e}$ & $6.07 \pm 0.02 \mathrm{e}$ & $726 \pm 9 \mathrm{def}$ & $105 \pm 4 \mathrm{bc}$ \\
Soil + PL 2\% & $6.83 \pm 0.00 \mathrm{~g}$ & $6.72 \pm 0.01 \mathrm{~g}$ & $941 \pm 343 \mathrm{fg}$ & $137 \pm 11 \mathrm{~d}$ \\
Soil + BPL 0.5\% & $6.57 \pm 0.01 \mathrm{f}$ & $6.21 \pm 0.04 \mathrm{f}$ & $443 \pm 33 \mathrm{bc}$ & $98 \pm 2 \mathrm{ab}$ \\
Soil + BPL 1\% & $7.10 \pm 0.03 \mathrm{~h}$ & $6.95 \pm 0.10 \mathrm{~h}$ & $434 \pm 65 \mathrm{bc}$ & $119 \pm 2 \mathrm{c}$ \\
Soil + BPL 2\% & $7.60 \pm 0.02 \mathrm{i}$ & $7.41 \pm 0.01 \mathrm{i}$ & $569 \pm 82 \mathrm{bcde}$ & $170 \pm 7 \mathrm{e}$ \\
\hline
\end{tabular}

Each value represents the mean of three replicates \pm standard deviation. The different letters within a column indicate a significant difference at $p \leq 0.05$ according to Duncan's multiple range tests.

PM: Pig manure, PL: poultry litter, PMB: pig manure biochar, PLB: poultry litter biochar. greater deacidifying effect of biochars was determined. The best results of the deacidifying effect were obtained after application of $1 \%$ and $2 \%$ amendment of biochars. This effect is due to a higher content of organic matter generates more output of alkali oxides which hydrolyze generate $\mathrm{OH}$ groups that increase the $\mathrm{pH}$ values (Lehmann et al., 2011; Inal et al., 2015). The results of our research confirm the observations made by Yuan et al. (2011), according to which alkaline substances are easier released from biochars than from materials which have not been subjected to thermal conversion. The process of thermal conversion brings about considerable changes in the chemism of biochars. Loss of compounds which are organic in nature in favor of mineral bonds takes place, which show greater potential for soil deacidification (Yuan et al., 2011). Moreover, the content of carbonates as well as of $\mathrm{Ca}$ and $\mathrm{Mg}$ cations (which are easily transferred into soil solution) increases (Van Zwieten et al., 2010). According to Cheng et al. (2006), application of biochar to soils may contribute to the release of acidifying substances as a result of chemical and microbiological processes taking place. Research results obtained by Liu and Zhang (2012) confirm the probability of occurrence of such a situation in a short period of time (4-mo after application). Inal et al. (2015) also report that application of PLB led to a reduction of $\mathrm{pH}$ in the alkaline soil. According to Liu and Zhang (2012), this may be caused by a release of functional groups of acidic character during oxidation of biochar. According to Atkinson et al. (2010), binding of Ca to P may take place in such conditions, which in consequence reduces the concentration of $\mathrm{Ca}$ ions in a soil solution.

Relatively to the quantity of materials used $(0.5 \%, 1 \%$, $2 \%$ ), the value of soil EC increased (Table 5). Higher EC values, regardless of the added amount of materials, were determined in the soil amended with PM and PL in the thermally unprocessed form. According to Solaiman and Anawar (2015), application of biochar to soil contributes significantly to a decrease in the content of salts easily soluble in a soil solution. This is connected with the sorption capacity of biochar, and this, in turn, arises from the process of production of the material (Nartey and Zhao, 2014). Moreover, the increase in soil EC values due to application of biochar was generally attributed to ash accretion as ash residues are generally dominated by carbonates of alkali and alkaline earth metals, variable amounts of silica, heavy metals, phosphates and small amounts of organic and inorganic N (Solaiman and Anawar 2015). Nigussie et al. (2012) also reported that the capacity of ashes to neutralize 
Table 6. Content of Mn and Fe in mobile forms and organic matter-bound forms in soil.

\begin{tabular}{|c|c|c|c|c|}
\hline Treatment & Fe mobile & $\begin{array}{l}\text { Fe bound to } \\
\text { organic matter }\end{array}$ & Mn mobile & $\begin{array}{l}\text { Mn bound to } \\
\text { organic matter }\end{array}$ \\
\hline Soil & $0.11+0.03 a$ & & $13.79+2.21 d$ & \\
\hline Soil + PM $0.5 \%$ & $0.90 \pm 0.12 \mathrm{~cd}$ & $791 \pm 23 \mathrm{ab}$ & $10.99 \pm 0.75 \mathrm{c}$ & $\begin{array}{l}47.3 \pm 5.5 \mathrm{a} \\
51.0 \pm 0.5 \mathrm{a}\end{array}$ \\
\hline Soil + PM $1 \%$ & $0.15 \pm 0.02 \mathrm{a}$ & $789 \pm 22 \mathrm{ab}$ & $9.76 \pm 0.89 c$ & $52.4 \pm 0.7 \mathrm{a}$ \\
\hline Soil + PM $2 \%$ & $2.42 \pm 0.02 \mathrm{e}$ & $834 \pm 27 b$ & $2.78 \pm 0.44 a$ & $54.9 \pm 2.5 \mathrm{a}$ \\
\hline Soil + BPM $0.5 \%$ & $0.32 \pm 0.12 \mathrm{ab}$ & $701 \pm 55 a$ & $6.94 \pm 0.38 b$ & $45.1 \pm 5.5 \mathrm{a}$ \\
\hline Soil + BPM 1\% & $0.29 \pm 0.02 \mathrm{ab}$ & $694 \pm 45 a$ & $3.57 \pm 0.36 \mathrm{a}$ & $49.9 \pm 7.4 \mathrm{a}$ \\
\hline Soil + BPM 2\% & $0.76 \pm 0.01 \mathrm{bcd}$ & $704 \pm 19 a$ & $1.24 \pm 0.24 \mathrm{a}$ & $50.3 \pm 3.8 \mathrm{a}$ \\
\hline Soil + PL $0.5 \%$ & $1.14 \pm 0.34 d$ & $772 \pm 49 a b$ & $6.30 \pm 0.29 b$ & $49.7 \pm 3.9 \mathrm{a}$ \\
\hline Soil + PL 1\% & $0.56 \pm 0.28 \mathrm{abc}$ & $784 \pm 17 a b$ & $2.60 \pm 0.20 \mathrm{a}$ & $56.1 \pm 7.8 \mathrm{a}$ \\
\hline Soil + PL 2\% & $0.40 \pm 0.16 a b c$ & $742 \pm 101 \mathrm{ab}$ & $1.38 \pm 0.12 \mathrm{a}$ & $49.9 \pm 7.0 \mathrm{a}$ \\
\hline Soil + BPL 0.5\% & $0.75 \pm 0.03 \mathrm{bcd}$ & $724 \pm 9 \mathrm{ab}$ & $2.54 \pm 0.33 a$ & $49.9 \pm 5.1 \mathrm{a}$ \\
\hline Soil + BPL 1\% & $0.76 \pm 0.01 \mathrm{bcd}$ & $682 \pm 47 a$ & $1.24 \pm 0.19 a$ & $52.0 \pm 2.9 \mathrm{a}$ \\
\hline Soil + BPL 2\% & $0.50 \pm 0.19 a b c$ & $733 \pm 7 \mathrm{ab}$ & $2.36 \pm 0.18 \mathrm{a}$ & $54.6 \pm 0.2 \mathrm{a}$ \\
\hline
\end{tabular}

Each value represents the mean of three replicates \pm standard deviation. The different letters within a column indicate a significant difference at $\mathrm{p} \leq 0.05$ according to Duncan's multiple range tests.

PM: Pig manure, PL: poultry litter, PMB: pig manure biochar, PLB: poultry litter biochar.

the acidic soil. In our presented research, application of PMB and PLB caused an increase in the value of EC in comparison with the soil from the control treatment, but to a lesser degree than application of unconverted PM and PL.

In general, the value of CEC was higher in treatments where organic materials had been applied than in the control. A greater increase in CEC, in comparison with the values of this parameter obtained after application of PM and PL, was observed after application of both biochars (PMB, PLB). The increase in the CEC value was also associated with the amount of added organic material. Numerous authors confirm the beneficial effect of biochar on the value of CEC of soils (Fellet et al., 2011; Yuan et al., 2011). As highlighted by Brodowski et al. (2005) and Cheng et al. (2006), an increase in soil CEC plays a substantial role in storage of water and of plant nutrients. This beneficial effect of biochar on the soil CEC should be attributed to physical features of biochar, mainly to the porous structure and specific surface area (Atkinson et al., 2010; Nartey and Zhao, 2014).

\section{Content of Fe and $\mathrm{Mn}$ in mobile forms and in OM-bound forms}

The effect of the used materials on mobility of Fe and Mn was examined after extraction of the most mobile forms of these elements with $1 \mathrm{M} \mathrm{NH}_{4} \mathrm{NO}_{3}$ solution (Table 6). The $2 \%$ amendment of PM and 1\% amendment of PL caused an increase in content of Fe forms extracted with $\mathrm{NH}_{4} \mathrm{NO}_{3}$ in comparison with the content determined in soil from the control treatment. The $2 \%$ amendment of PMB caused an increase in the content of mobile forms of $\mathrm{Fe}$, whereas in the case of amendment of PLB we recorded a decrease in mobility of this element.

The addition of organic materials to the soil caused a reduction in the content of mobile forms of Mn (Table 6). The amendment of PM to the soil contributed to a decrease in mobility of Mn from $20 \%$ to $80 \%$, whereas the amendment of PL from 54\% to 90\%. Higher values of Mn immobilization were obtained with the larger addition of organic materials.
Application of PMB and PLB to the soil caused a similar immobilization of mobile forms of mobile forms of Mn.

Based on the sequential chemical extraction developed by Zeien and Brümmer (1989), the content of trace elements in fraction bound to soil OM was determined. It has been shown that the content of $\mathrm{Fe}$ and $\mathrm{Mn}$ extracted with $0.025 \mathrm{M}$ $\mathrm{C}_{10} \mathrm{H}_{22} \mathrm{~N}_{4} \mathrm{O}_{8}$ was higher than the content of these elements extracted with $1 \mathrm{MNH}_{4} \mathrm{NO}_{3}$, mainly due to different extraction force of the solutions (Al-Wabel et al., 2015). The obtained results indicate that the amendment of organic materials to the soil did not have much effect on the content of Fe and Mn in the organic fraction (Table 6). When comparing the effect of PM and PL amendments with biochars produced from these materials (PMB, PLB), it was found that the content of $\mathrm{Fe}$ and $\mathrm{Mn}$ after application of unconverted and thermally converted materials was comparable.

The research results published so far indicate, that application of biochar to soil can cause liming effect as a result of decomposition of carbonates and hydroxides which are present in biochar. This, in consequence, may have a significant effect on the mobility of trace elements (Lucchini et al., 2014). In our research, we observed no directed changes in Fe mobility as well as a considerable decrease in Mn mobility. Undoubtedly, the considerable increase in soil $\mathrm{pH}$ as a result of application of organic materials (especially biochars) contributed to this. The obtained research results on the decrease in Mn mobility find confirmation in the results published by Al-Wabel et al. (2015). Reduction of acidification led to formation of poorly soluble Mn compounds in the soil. It should also be highlighted that the highly porous structure of biochar and the presence of functional groups did not have a significant impact on adsorption of $\mathrm{Fe}$ and $\mathrm{Mn}$. According to Al-Wabel et al. (2015), amendment of biochar to soil has an effect on the content of available forms of both $\mathrm{Fe}$ and $\mathrm{Mn}$. Fellet et al. (2011) also showed that biochar reduces the mobility of trace elements. Application of biochar may lead to changes of easily available forms of trace elements into forms which are chemically more stable, which in consequence causes a 
reduction in their mobility and bioavailability (Ahmad et al., 2014a). According to Park et al. (2011), Usman et al. (2013), and Ahmad et al. (2014b), immobilization of trace elements in biochar-amended soil can be attributed to several chemical processes, including ion exchange, chemical sorption, and complexing on the surface. According to Park et al. (2011) and Usman et al. (2013), immobilization of trace elements in soil may take place as a result of precipitation with such mineral components as carbonates, silicates and phosphates. Choppala et al. (2012) reported that biochars can also limit the mobility of trace elements by altering the redox potential, exemplifying this in the effect of biochar amendment to soil on the changes of $\mathrm{Cr}^{+6}$ to $\mathrm{Cr}^{+3}$. The relative participation of individual mechanisms in immobilization of trace elements after application of biochar remains unknown, although according to some authors like Houben et al. (2013), change in soil reaction $(\mathrm{pH})$ is the main deciding factor.

\section{CONCLUSIONS}

The determined content of total forms of $\mathrm{Mn}$ and $\mathrm{Fe}$ in biochars was much higher compared to the content determined in the unconverted materials (pig manure $[\mathrm{PM}]$, poultry litter [PL]). As a result of thermal conversion of organic materials, PM and PL, a significant reduction in the content of Mn and $\mathrm{Fe}$ forms extracted with water was observed. The $2 \%$ amendment of PM biochar (PMB) caused an increase in the content of mobile forms of $\mathrm{Fe}$, whereas in the case of the same dose of PL biochar (PLB) we recorded a decrease in mobility of this element. Application of PMB and PLB to the soil caused a similar immobilization of mobile forms of manganese as in the case of application of PM and PL that had not been thermally converted. The conducted research suggests that biochar can be a material that decreases bioavailability of trace elements which are potentially toxic for plants. It also indicates that biochar application to soil may have an effect on translocation and diffusion of trace elements (which depends on biochar porosity and presence of surface functional groups) in soil.

\section{ACKNOWLEDGEMENTS}

The Research was financed by the Ministry of Science and Higher Education of the Republic of Poland.

\section{REFERENCES}

Ahmad, M., S.S. Lee, J.E. Lim, S.-E. Lee, J.S. Cho, D.H. Moon, et al. 2014a. Speciation and phytoavailability of lead and antimony in a small arms range soil amended with mussel shell, cow bone and biochar: EXAFS spectroscopy and chemical extractions. Chemosphere 95:433-441. doi:10.1016/j. chemosphere.2013.09.077.

Ahmad, M., A.U. Rajapaksha, J.E. Lim, M. Zhang, D.M. Bolan, M. Vithanage, et al. 2014b. Biochar as a sorbent for contaminant management in soil and water: A review. Chemosphere 99:19-33. doi:10.1016/j.chemosphere.2013.10.071.
Al-Wabel, M.I., A. Al-Omran, A.H. El-Naggar, M. Nadeem, and A.R.A. Usman. 2013. Pyrolysis temperature induced changes in characteristics and chemical composition of biochar produced from conocarpus wastes. Bioresource Technology 131:374-379. doi:10.1016/j.biortech.2012.12.165.

Al-Wabel, M.I., A.R.A. Usman, A.H. El-Naggar, A.A. Aly, H.M. Ibrahim, S. Elmaghraby, et al. 2015. Conocarpus biochar as a soil amendment for reducing heavy metal availability and uptake by maize plants. Saudi Journal of Biological Sciences 22:503511. doi:10.1016/j.sjbs.2014.12.003.

Atkinson, C.J., J.D. Fitzgerald, and N.A. Hipps. 2010. Potential mechanisms for achieving agricultural benefits from biochar application to temperate soil: a review. Plant and Soil 337:1-18. doi:10.1007/s11104-010-0464-5.

Barrett,E.P.,L.G. Joyner, and P.H.Halenda. 1951. The determination of pore volume and area distributions in porous substances. I. Computations from nitrogen isotherms. Journal of the American Chemical Society 73(1):373-380. doi:10.1021/ja01145a126.

Brodowski, S., W. Amelung, L. Haumaier, C. Abetz, and W. Zech. 2005. Morphological and chemical properties of black carbon in physical soil fractions as revealed by scanning electron microscopy and energy-dispersive x-ray spectroscopy. Geoderma 128:116-129. doi:10.1016/j.geoderma.2004.12.019.

Commission Regulation. 2003. Commission Regulation (EC) No 1334/2003 of 25 July 2003 amending the conditions for authorisation of a number of additives in feeding stuffs belonging to the group of trace elements. Official Journal of the European Union L 187/11, 26.7.2003. 5 p.

Cheng, C.H., J. Lehmann, J.E. Thies, S.D. Burton, and M.H. Engelhard. 2006. Oxidation of black carbon by biotic and abiotic processes. Organic Geochemistry 37:1477-1488. doi:10.1016/j. orggeochem.2006.06.022.

Choppala, G.K., N.S. Bolan, M. Megharaj, Z. Chen, and R. Naidu. 2012. The influence of biochar and black carbon on reduction and bioavailability of chromate in soils. Journal of Environmental Quality 41:1175-1184. doi:10.2134/jeq2011.0145.

Enders, A., K. Hanley, T. Whitman, S. Joseph, and J. Lehmann. 2012. Characterization of biochars to evaluate recalcitrance and agronomic performance. Bioresource Technology 114:644-653. doi:10.1016/j.biortech.2012.03.022.

Fellet, G., L. Marchiol, G. Delle Vedove, and A. Peressotti. 2011. Application of biochar on mine tailings: Effects and perspectives for land reclamation. Chemosphere 83:1262-1267. doi:10.1016/j. chemosphere.2011.03.053.

Gondek, K., A. Baran, and M. Kopec. 2014. The effect of lowtemperature transformation of mixtures of sewage sludge and plant material on content, leachability and toxicity of heavy metals. Chemosphere 117:33-39. doi:10.1016/j. chemosphere.2014.05.032.

Han, Y., A.A. Boateng, P.X. Qi, I.M. Lima, and J. Chang. 2013. Heavy metal and phenol adsorptive properties of biochars from pyrolyzed switchgrass and woody biomass in correlation with surface properties. Journal of Environmental Management 118:196-204. doi:10.1016/j.jenvman.2013.01.001.

He, Y.D., Y.B. Zhai, C.T. Li, F. Yang, L. Chen, X.P. Fan, et al. 2010. The fate of $\mathrm{Cu}, \mathrm{Zn}, \mathrm{Pb}$ and $\mathrm{Cd}$ during the pyrolysis of sewage sludge at different temperatures. Environmental Technology 35(5):567-574. doi:10.1080/09593330903514466.

Hossain, M.K., V. Strezov, K.Y. Chan, A. Ziólkowski, and P.F. Nelson. 2011. Influence of pyrolysis temperature on production and nutrient properties of wastewater sludge biochar. Journal of Environmental Management 92(1):223-228. doi:10.1016/j. jenvman.2010.09.008. 
Houben, D., L. Evrard, and P. Sonnet. 2013. Mobility, bioavailability and $\mathrm{pH}$-dependent leaching of cadmium, zinc and lead in a contaminated soil amended with biochar. Chemosphere 92:14501457. doi:10.1016/j.chemosphere.2013.03.055.

IBI. 2012. Standardized product definition and product testing guidelines for biochar that is used in soil. International Biochar Initiative (IBI). Available at http://www.biochar-international. org/sites/default/files/Guidelines_for_Biochar_That_Is_Used_ in_Soil_Final.pdf (accessed 14 March 2015).

Inal, A., A. Gunes, O. Sahin, M.B. Taskin, and E.C. Kaya. 2015. Impacts of biochar and processed poultry manure, applied to a calcareous soil, on the growth of bean and maize. Soil Use and Management 31:106-113. doi:10.1111/sum.12162.

Jaremko, D., and D. Kalembasa. 2014. A comparison of method for the determination of cation exchange capacity of soils. Ecological Chemistry and Engineering S 21(3):487-498. doi:10.2478/eces2014-0036.

Jindo, K., H. Mizumoto, Y. Sawada, M.A. Sanchez-Monedero, and T. Sonoki. 2014. Physical and chemical characterization of biochars derived from different agricultural residues. Biogeosciences 11:6613-6621. doi:10.5194/bg-11-6613-2014.

Jindo, K., K. Suto, K. Matsumoto, C. Garcia, T. Sonoki, and M.A. Sanchez-Monedero. 2012. Chemical and biochemical characterisation of biochar-blended composts prepared from poultry manure. Bioresource Technology 110:396-404. doi:10.1016/j.biortech.2012.01.120.

Kobierski, M. 2004. Copper, zinc, manganese and iron concentrations in soils of 27 and 30-year-old Apple tree orchards. Acta Scientiarum Polonorum Hortorum Cultus 3(2):161-170 (in Polish).

Lehmann, J., M.C. Rilling, J. Thies, C.A. Masiello, W.C. Hockaday, and D. Crowley. 2011. Biochar effects on soil biota. A review. Soil Biotechnology and Biochemistry 43:1812-1836. doi:10.1016/j. soilbio.2011.04.022.

Liu, X.H., and X.C. Zhang. 2012. Effect of biochar on pH of alkaline soils in the loess plateau: results from incubation experiments. International Journal of Agriculture and Biology 14:745-750. doi:10.1016/S1002-0160(15)30052-7.

Livens, F. 1991. Chemical reactions of metals with humic material. Environmental Pollution 70:183-208. doi:10.1016/02697491(91)90009-L.

Lucchini, P., R.S. Quilliam, T.H. DeLuca, T. Vamerali, and D.L. Jones. 2014. Does biochar application alter heavy metal dynamics in agricultural soil? Agriculture, Ecosystems \& Environment 184:149-157. doi:10.1016/j.agee.2013.11.018.

Meier, S., G. Curaqueo, N. Khan, N. Bolan, J. Rilling, C. Vidal, et al. 2015. Effect of biochar on copper immobilization and soil microbial communities in a metal-contaminated soil. Journal of Soils and Sediments p. 1-14. doi:10.1007/s11368- 015-1224-1.

Nartey, O.D., and B. Zhao. 2014. Biochar preparation, characterization, and adsorptive capa city and its effect on bioavailability of contaminants: an overview. Advances in Materials Science and Engineering Volume 2014 Article ID 715398, 12 p. doi:10.1155/2014/715398.

Nigussie, A., E. Kissi, M. Misganaw, and G. Ambaw. 2012. Effect of biochar application on soil properties and nutrient uptake of lettuces (Lactuca sativa) grown in chromium polluted soils. American-Eurasian Journal of Agricultural \& Environmental Sciences 12(3):369-376. doi:10.1111/gcbb.12037.
Novak, J.M., I. Lima, B. Xing, J.W. Gaskin, C. Steiner, K.C. Das, et al. 2009. Characterization of designer biochar produced at different temperatures and their effects on a loamy sand. Annals of Environmental Science 3:195-206.

Oleszczuk, N., J.T. Castro, M.M. da Silva, Md. Korn, B. Welz, and M.G. Vale. 2007. Method development for the determination of manganese, cobalt and copper in green coffee comparing direct solid sampling electrothermal atomic absorption spectrometry and inductively coupled plasma optical emission spectrometry. Talanta 73(5):862-869. doi:10.1016/j.talanta.2007.05.005.

Park, J.H., G.K. Choppala, N.S. Bolan, J.W. Chung, and T. Chusavathi. 2011. Biochar reduces the bioavailability and phytotoxicity of heavy metals. Plant and Soil 348:439-451. doi:10.1007/s11104-011-0948-y.

Samsuri, A.W., F. Sadegh-Zadeh, and B.J. Seh-Bardan. 2013. Adsorption of $\mathrm{As}(\mathrm{III})$ and $\mathrm{As}(\mathrm{V})$ by $\mathrm{Fe}$ coated biochars and biochars produced from empty fruit bunch and rice husk. Journal of Environmental Chemical Engineering 1(4):981-988. doi:10.1016/j.jece.2013.08.009.

Solaiman, Z.N., and H.M. Anawar. 2015. Application of biochars for soil constraints: challenge and solutions. Pedosphere 25(5):631-638. doi:10.1016/S1002-0160(15)30044-8.

Song, W., and M. Guo. 2012. Quality variations of poultry litter biochar generated at different pyrolysis temperatures. Journal of Analytical and Applied Pyrolysis 94:138-145. doi:10.1016/j. biortech.2015.10.016.

Usman, A.R.A., A.S. Sallam, A.Al-Omran, A.H.El-Naggar, K.K.H. Alenazi, M. Nadeem, et al. 2013. Chemically modified biochar produced from conocarpus wastes: an efficient sorbent for $\mathrm{Fe}(\mathrm{II})$ removal from acidic aqueous solutions. Adsorption Science \& Technology 31:625-640. doi:10.1007/s 10653-015-9736-6.

Walna, B., W. Spychalski, and A. Ibragimow. 2010. Fractionation of iron and manganese in the horizons of a nutrient-poor forest soil profile using the sequential extraction method. Polish Journal of Environmental Studies 19(5):1029-1037.

Van Zwieten, L., S. Kimber, S. Morris, K. Chan, A. Downie, J. Rust, et al. 2010. Effects of biochar from slow pyrolysis of papermill waste on agronomic performance and soil fertility. Plant and Soil 327:235-246. doi:10.1007/s11104-009-0050-x.

Xue, N., H.M. Seip, J. Guo, B. Liao, and Q. Zeng. 2006. Distribution of $\mathrm{Al}, \mathrm{Fe}, \mathrm{Mn}$ pools and their correlation in soils from two acid deposition small catchments in Hunan, China. Chemosphere 65(11):2468-2476. doi:10.1016/j.chemosphere.2006.04.045.

Yuan, J., R. Xu, N. Wang, and J. Li. 2011. Amendment of acid soils with crop residues and biochars. Pedosphere 21:302-308. doi:10.1016/S1002-0160(11)60130-6.

Zeien, H., und G.W. Brümmer. 1989. Chemische extraktion zur bestimmung von schwermetall bindungsformen in böden. Mitteilungen Deutsche Bodenkundliche Gesellschaft 59:505-510. 